\title{
If a man buys a horse, ... you have no argument against material implication: On a flaw in the foundations of the restrictor approach to conditionals
}

\author{
Carsten Breul \\ (Bergische Universität Wuppertal, Germany)
}

\begin{abstract}
Note: This contribution consists of two parts: a paper that was submitted to a peer reviewed journal and rejected on the basis of a review by an anonymous reviewer; an appendix that contains my comments on the points made in this review. Since these points are invalid or inconclusive, as I show in my comments, I do not feel that they ought to be reflected in a new version of the paper. Rather, I feel that the discussion of these points within the paper would run the danger of damaging its coherence and that assigning the discussion to an appendix is thus preferable.
\end{abstract}

\begin{abstract}
The paper discusses a prominent one of Kratzer's $(1986,1991,2012)$ arguments against material implication analyses of the denotation of (indicative) conditional sentences. This is the argument based on the sentence Most of the time, if a man buys a horse, he pays cash for it. It is shown that material implication makes a prediction that does conform to speakers' intuitions, contrary to Kratzer's claim. The paper also argues that Lewis's (1975) attack on material implication analyses of conditional sentences based on examples where the conditional is embedded under the adverbials sometimes and never does not have much force given that the interpretation of such sentences is subject to inferential pragmatic operations in addition to the recovery of their denotation.
\end{abstract}

\section{Keywords}

conditional sentence, restrictor approach, material implication approach

\section{The restrictor approach to conditionals and Kratzer's horse sale argument}

The restrictor approach to (or restrictor view / analysis / theory of) natural language conditional sentences represents a very prominent and influential theoretical framework for the analysis of the meaning of such sentences in linguistic semantics and pragmatics as well as the philosophy of language (see e.g. Edgington 2001/2014: section 4.3, Kaufmann \& Kaufmann 2015: 246, 254-255, Liu 2019: 2). It is presented as the "dominant approach" to conditionals in linguistics by von Fintel (2011: 1524; likewise Cantwell 2018: 139), who points out that

[f]ollowing Partee (1991), the restrictor theory of if-clauses is sometimes called the "Lewis/Kratzer/Heim" analysis (henceforth restrictor), because after the initial 
idea of Lewis and the generalization by Kratzer, the application of the story to the analysis of donkey anaphora by Heim (1982) played a large role in the triumph of the theory in linguistic circles. (von Fintel 2011: 1526)

The reference to Lewis here is Lewis (1975), in which it is argued that in sentences of the form \{Always / Sometimes / Never\}, if P (then) $Q$, "the if of our restrictive if-clauses should not be regarded as a sentential connective. It has no meaning apart from the adverb it restricts" (Lewis 1975: 11). This idea is taken up by Kratzer $(1986,1991,2012) .{ }^{1}$ After diagnosing a "steady decline of the material conditional" in the "recent history of semantics" (Kratzer 2012: 88), she characterises Lewis's argument as a "more direct attack" (Kratzer 2012: 89) on an analysis of conditionals as denoting material implication. For Kratzer, Lewis (1975) shows that "there are indicative conditionals that cannot be analyzed as material conditionals" (Kratzer 2012: 91). The generalisation that von Fintel (see above) refers to consists in Kratzer's conclusion that clauses complementing if generally do not play the role of an antecedent in material implication. Rather, "[i]f-clauses need to be parsed as adverbial modifiers that restrict operators that might be silent and a distance away. This is what we might call 'the restrictor view' of if-clauses" (Kratzer 2012: 107). That is, according to this view, it is generally inadequate to analyse an (English) indicative conditional as denoting a material implication relation between the if-clause and its matrix clause.

Kratzer summarises the gist of Lewis (1975) by way of the following argument, containing what is considered to be a refutation of the material implication approach $\left(' \rightarrow\right.$ ' symbolising material implication) $:^{2}$

[s]uppose the logical form of [(1a)] were [(1b)]:

[(1)] a. Most of the time, if a man buys a horse, he pays cash for it.

b. For most events e ( $(\mathrm{e}$ is an event where a man buys a horse $) \rightarrow(\mathrm{e}$ is part of an event where the man in e pays cash for the horse in e)).

If formalized as [(1b)], [(1a)] should be true on a scenario where, say, out of a million events of some kind or other, 2000 are events where a man buys a horse, and, out of those, 1990 are sales that are settled by check. [(1a)] is intuitively false on such a scenario, since most of the horse sales are not settled by cash. [(1b)] comes out true, however, since most of the one million events that make up the domain of quantification are not events where a man buys a horse to begin with.

The problem can be solved by adopting restricted quantification structures for adverbial quantifiers, too.

[(2)] (Most e: e is an event where a man buys a horse) (e is part of an event where the man in e pays cash for the horse in e).

$[\ldots][(2)]$ is true just in case most events that satisfy the quantifier restriction also satisfy the nuclear scope. (Kratzer 2012: 90)

This reasoning, which has never been convincingly refuted (but see Smith \& Smith 1988: 338-339 for a decidedly skeptical attitude towards it), distorts to a contradictory degree what the material implication approach to conditionals predicts about a sentence

\footnotetext{
${ }^{1}$ Kratzer (2012) is a revised and expanded version of Kratzer (1991), which is a reprint of Kratzer (1986). I quote from Kratzer (2012).

${ }^{2}$ The argument is explicitly endorsed by Reed (1999: 313).
} 
like (1a) and thus does not constitute a piece of evidence against this approach, as will now be shown.

\section{A refutation of the horse sale argument}

(3) below is the material implication in the scope of the quantifier for most events $e$ in Kratzer's representation (1b) of the material implication analysis of the conditional in (1a).

(3) (e is an event where a man buys a horse) $\rightarrow$ (e is part of an event where the man in e pays cash for the horse in e)

Let us consider how many events exactly render (3) true in Kratzer's horse sale scenario. Material implication predicts that (3) is false if the antecedent is true and the consequent is false; otherwise (3) is true. That is, in this scenario, (3) is false for 1990 events - these are the events where a man buys a horse and does not pay cash - and thus is true for $1000000-1990=998010$ events.

Kratzer's argument is this: the material implication analysis makes a false prediction; it predicts that (1a) is true since the number of events for which (3) is true is 998010, which is more than the number of "horse sales [...] not settled by cash" (see quotation above), i.e. the number of horse sales settled by cheque, namely 1990. This argument is wrong. In a material implication analysis of conditionals in the scope of the adverbial most of the time (rendered as for most events $e$ in Kratzer's logical form; see quotation above), it is wrong to compare the number of events for which the conditional is true with the number of events for which the consequent of the conditional is false. What has to be compared is the number of events for which the conditional is true and the number of events for which the contextually relevant alternative conditionals are true. ${ }^{3}$ Since there is only one contextually relevant alternative conditional in Kratzer's scenario, namely If a man buys a horse, he pays for it by cheque, the number of events for which (3) is true has to be compared with the number of events for which (4) is true.

(4) (e is an event where a man buys a horse) $\rightarrow$ (e is part of an event where the man in e pays for the horse in e by cheque)

Again, of course, material implication predicts that (4) is false if the antecedent is true and the consequent is false; otherwise (4) is true. That is, in Kratzer's scenario, (4) is false for 10 events - these are the events where a man buys a horse and does not pay by cheque - and thus is true for $1000000-10=999990$ events. These are more events than those for which (3) is true, i.e. $998010 .^{4}$ That is, the material implication analysis (1b)

\footnotetext{
${ }^{3}$ On the role of contextually relevant alternatives for the evaluation of expressions in the scope of superlatives see Hackl (2009), Heim (1999), Kotek \& Sudo \& Howard \& Hackl (2011), Krifka (1992), Sharvit $\&$ Stateva (2002) among others.

${ }^{4}$ Note also that (1b) above is equivalent to (i):

(i) For most events e ( $(\mathrm{e}$ is not an event where a man buys a horse) $\vee(\mathrm{e}$ is part of an event where the man in e pays cash for the horse in e))

Obviously, in order to evaluate whether this is true in Kratzer's scenario, the number of events for which the disjunction is true has to be compared with the number of events for which the disjunction in (ii) below is true, which is equivalent to the material implication contained in (4) above, not with the number of events for which just the second disjunct of (ii) is true:
} 
of the conditional sentence in (1a) does not predict that (1a) is true in this scenario, contrary to what Kratzer claims. Material implication predicts that (1a) is false, which is in accordance with the intuitive evaluation of the sentence in this scenario.

\section{A discussion of modified horse sale arguments}

A modification of Kratzer's argument does appear to go through, though, for another quantifying adverbial than most of the time or mostly, namely sometimes. Let us consider a scenario where there are 1000000 events of some kind or other, of which 2000 are horse sales, of which all are settled by cheque, i.e. none settled by cash. Intuitively, (5) is false in this scenario.

(5) Sometimes (i.e. 'For some events e'), if a man buys a horse, he pays cash for it.

Indeed, material implication predicts otherwise. It predicts that the conditional within the scope of the adverbial is false for 2000 events, that is, it predicts that the sentence is sometimes (i.e. $1000000-2000=998000$ times) true, contradicting the intuition for (5). Even so, this does not constitute an argument that proves the inadequacy of the material implication approach, as will now be shown.

Let us look at what the quantified expression sometimes' $(P \rightarrow Q)$ in general denotes in terms of set theory. Given the domain of events $D=P_{\text {true }} \cup P_{\text {false }} \neq \varnothing$, if $P_{\text {true }}$ is the set of events for which $P$ is true, $P_{\text {false }}$ the set of events for which $P$ is false, $Q_{\text {true }}$ the set of events for which $Q$ is true and $Q$ false the set of events for which $Q$ is false, the material implication $P \rightarrow Q$ denotes the set $E$ of events in (6).

$$
\mathrm{E}=\left(\mathrm{P}_{\text {true }} \cup \mathrm{P}_{\text {false }}\right) \backslash\left(\mathrm{P}_{\text {true }} \cap \mathrm{Q}_{\text {false }}\right)
$$

$P_{\text {true }}$ and $P_{\text {false }}$ are disjoint and together exhaust $D$; the same holds for $Q_{\text {true }}$ and $Q_{\text {false. }}$ The quantified expression sometimes' $(P \rightarrow Q)$, then, denotes the set $\mathcal{S}$ of sets of events for which (7) holds.

$$
\begin{aligned}
& S=\left\{\mathrm{E} \mid \mathrm{E}=\left(\mathrm{P}_{\text {true }} \cup \mathrm{P}_{\text {false }}\right) \backslash\left(\mathrm{P}_{\text {true }} \cap \mathrm{Q}_{\text {false }}\right) \neq \varnothing\right\} \\
& \Leftrightarrow S=\left\{\mathrm{E} \mid \mathrm{E}=\left(\mathrm{P}_{\text {true }} \backslash\left(\mathrm{P}_{\text {true }} \cap \mathrm{Q}_{\text {false }}\right)\right) \cup\left(\mathrm{P}_{\text {false }} \backslash\left(\mathrm{P}_{\text {true }} \cap \mathrm{Q}_{\text {false }}\right)\right) \neq \varnothing\right\} \\
& \Leftrightarrow S=\left\{\mathrm{E} \mid \mathrm{E}=\left(\mathrm{P}_{\text {true }} \backslash\left(\mathrm{P}_{\text {true }} \cap \mathrm{Q}_{\text {false }}\right)\right) \cup \mathrm{P}_{\text {false }} \neq \varnothing\right\} \\
& \Leftrightarrow S=\left\{\mathrm{E} \mid \mathrm{E}=\left(\left(\mathrm{P}_{\text {true }} \backslash \mathrm{P}_{\text {true }}\right) \cup\left(\mathrm{P}_{\text {true }} \backslash \mathrm{Q}_{\text {false }}\right)\right) \cup \mathrm{P}_{\text {false }} \neq \varnothing\right\} \\
& \Leftrightarrow S=\left\{\mathrm{E} \mid \mathrm{E}=\left(\mathrm{P}_{\text {true }} \backslash \mathrm{Q}_{\text {false }}\right) \cup \mathrm{P}_{\text {false }} \neq \varnothing\right\} \\
& \Leftrightarrow S=\left\{\mathrm{E} \mid \mathrm{E}=\left(\mathrm{P}_{\text {true }} \cap \mathrm{Q}_{\text {true }}\right) \cup \mathrm{P}_{\text {false }} \neq \varnothing\right\} \\
& \Leftrightarrow S=\left\{\mathrm{E} \mid \mathrm{E}=\mathrm{P}_{\text {true }} \cap \mathrm{Q}_{\text {true }} \neq \varnothing \vee \mathrm{E}=\mathrm{P}_{\text {false }} \neq \varnothing\right\}
\end{aligned}
$$

This means that a communicator who utters a conditional sentence in the scope of sometimes can be taken to intend to convey $P_{\text {true }} \cap Q_{\text {true }} \neq \varnothing$ or $P_{\text {false }} \neq \varnothing$ or $P_{\text {true }} \cap Q_{\text {true }} \neq \varnothing$ $\wedge P_{\text {false }} \neq \varnothing$. Now, if it is mutually manifest to the communicator and the interpreter that $P_{\text {false }} \neq \varnothing,{ }^{5}$ as it is for an interpreter of an utterance of (5) who is informed about the scenario mentioned, the communicator can be taken to intend to convey $P_{\text {true }} \cap Q_{\text {true }} \neq$

(ii) For most events e ((e is not an event where a man buys a horse) $\vee$ (e is part of an event where the man in e pays for the horse in e by cheque))

${ }^{5}$ On mutual manifestness see Sperber \& Wilson (1995: 38-46, 60-64). 
$\varnothing^{6}$ This is false in the scenario for (5), which explains, on the basis of an inferential pragmatic consideration, the apparent contradiction between our intuition about (5) and the prediction generated by the material implication analysis of it.

This analysis has the advantage of providing an immediate account of the fact that it is possible to convey 'Trump never considers the environmental risks of fracking' by uttering (8).

(8) Sometimes, if Trump considers the environmental risks of fracking, Bolsonaro considers the environmental risks of the destruction of the Amazon rainforest.

For this to happen, the communicator needs to assume that the interpreter brings the assumption 'Bolsonaro never considers the environmental risks of the destruction of the Amazon rainforest' to bear on the interpretation of (8). For then, $P_{\text {true }} \cap Q_{\text {true }}=\varnothing$, which deductively yields $\mathcal{S}=\left\{E \mid E=P_{\text {false }} \neq \varnothing\right\}$ from (7).

The modification of Kratzer's argument appears to go through for never as well. ${ }^{7}$ Yet again, this does not entail that the material implication approach is inadequate. Consider (9) in the same scenario as provided for (5).

(9) The following is never true: If a man buys a horse, he pays cash for it. ${ }^{8}$

Intuitively, (9) is true in this scenario. However, material implication predicts that the conditional within the scope of the adverbial is false for 2000 events and true for 998000 events, thus not never true, contradicting intuition. In terms of set theory, the quantified expression never' $(P \rightarrow Q)$ in general denotes the set $S_{\text {of sets of events for }}$ which (10) holds.

$$
\begin{aligned}
& S=\left\{\mathrm{E} \mid \mathrm{E}=\left(\mathrm{P}_{\text {true }} \cup \mathrm{P}_{\text {false }}\right) \backslash\left(\mathrm{P}_{\text {true }} \cap \mathrm{Q}_{\text {false }}\right)=\varnothing\right\} \\
& \Leftrightarrow S=\left\{\mathrm{E} \mid \mathrm{E}=\left(\mathrm{P}_{\text {true }} \cap \mathrm{Q}_{\text {false }}\right) \cup \mathrm{P}_{\text {false }}=\varnothing\right\}(\text { cf. }(7) \text { up to the last but one line }) \\
& \Leftrightarrow S=\left\{\mathrm{E} \mid \mathrm{E}=\left(\mathrm{P}_{\text {true }} \cap \mathrm{Q}_{\text {true }}\right)=\varnothing \wedge \mathrm{E}=\mathrm{P}_{\text {false }}=\varnothing\right\}
\end{aligned}
$$

This means that a communicator who utters a conditional sentence in the scope of never can be taken to intend to convey $P_{\text {true }} \cap Q_{\text {true }}=\varnothing \wedge P_{\text {false }}=\varnothing$ in principle. Now, in the respective scenario it is mutually manifest to the communicator and the interpreter that $P_{\text {false }} \neq \varnothing$. Consequently, (10) denotes the empty set on the assumption that $D=P_{\text {true }} U$ $P_{\text {false }}$ is the set of 1000000 events in all. In order for an utterance of (9) to be true, $\mathcal{S}$ must not denote the empty set $\varnothing$, but the set $\{E \mid E=\varnothing\}$. The only set $D$ for which $S=$ $\{E \mid E=\varnothing\}$ in this scenario is the set where $D$ equals $P_{\text {true, }}$ i.e. where $D$ is the set of the 2000 horse sales settled by cheque. On the inferred assumption that this is the domain of

\footnotetext{
${ }^{6}$ This follows in any Gricean (Grice 1989) or post-Gricean theory of inferential linguistic pragmatics (such as Levinson 2000, Sperber \& Wilson 1995) from the pragmatic principles that model what one can informally call the requirement for informativity or relevance of utterances.

${ }^{7}$ Sometimes and never are the adverbials which Lewis (1975: 11) says prevent a material implication analysis of conditionals in their scope.

${ }^{8}$ I use this example in order to avoid a discussion of the potential cause or effect on meaning of $d o$-support cum subject-do inversion in (ia) and a discussion of whether or under what circumstances (ib) is a grammatical sentence.

(i) a. Never, if a man buys a horse, does he pay cash for it.

b. $\quad *(?)$ Never, if a man buys a horse, he pays cash for it.

Interestingly, Lewis (1975: 9) uses an example with do-support and inversion, in line with common English usage (see Jacobsson 2007), while Kratzer (2012: 89) uses (ib) above, referring to Lewis (1975). Neither comments on this issue.
} 
events $D$ with respect to which the communicator utters (9), the material implication analysis of (9) is true, which accounts for the intuition about it in the given scenario. This account holds analogically for all cases of an (indicative) conditional sentence if $P$ (then) $Q$ in the scope of never when it is mutually manifest to communicator and interpreter that $P_{\text {false }} \neq \varnothing$. $^{9}$

In both cases just discussed - sometimes' $(P \rightarrow Q)$ and never' $(P \rightarrow Q)$ - the mutual manifestness of $P_{\text {false }} \neq \varnothing$ leads to the inferentially gained conclusion that the former yields (11a) and the latter (11b).

$$
\begin{array}{ll}
\text { a. } & S=\left\{\mathrm{E} \mid \mathrm{E}=\left(\mathrm{P}_{\text {true }} \cap \mathrm{Q}_{\text {true }}\right) \neq \varnothing\right\} \\
\text { b. } & S=\left\{\mathrm{E} \mid \mathrm{E}=\left(\mathrm{P}_{\text {true }} \cap \mathrm{Q}_{\text {true }}\right)=\varnothing\right\}
\end{array}
$$

This is equivalent to Lewis's (1975: 11) observation that the meaning of a conditional sentence if $P$ (then) $Q$ in the scope of sometimes or never is sometimes' $(P \wedge Q)$ and never' $(P \wedge Q)$ respectively. On the present approach, this is inferentially derived on the basis of a material implication analysis given that it is mutually manifest to communicator and interpreter that $P_{\text {false }} \neq \varnothing$.

How are conditionals in the scope of mostly or most of the time, as in Kratzer's (2012) original sentence (1a), to be analysed in terms of a set theoretic version of the material implication approach? The quantified expression mostly' $(P \rightarrow Q)$ denotes the set $\mathcal{S}$ of sets $X$ of events for which (12) below holds, where \# $X$ symbolises the cardinality of some set $X$ and where $A$ is a (proper or improper) subset of $D=\left(P_{\text {true }} \cup P_{\text {false }}\right)$ different from the set denoted by the conditional in the scope of mostly or most of the time, i.e. different from $\left(P_{\text {true }} \cup P_{\text {false }}\right) \backslash\left(P_{\text {true }} \cap Q_{\text {false }}\right)$. That is, $A$ is the denotation of a contextually relevant alternative to the conditional in the scope of mostly or most of the time, whose cardinality has to be smaller than the cardinality of $\left(P_{\text {true }} \cup P_{\text {false }}\right) \backslash\left(P_{\text {true }} \cap\right.$ $\left.Q_{\text {false }}\right)$ for (1a) to be true. From a purely truth-conditional perspective, mostly' $(P \rightarrow Q)$ is true if, and only if, (12) is true for every $A$ (hence $\forall A$ ), but in communicative uses of corresponding sentences, $A$ is constrained to be the denotation of a pragmatically (comprising considerations of information structure) determined alternative to the conditional in the scope of mostly or most of the time. (That information structure plays a role as well becomes obvious when considering that the utterance of Most of the time, if a man buys a horse HE pays cash for it (not his wife) triggers different assumptions about $A$ than the original example, where cash is implicitly assumed to be the carrier of the main sentence accent. ${ }^{10}$ )

$$
\begin{aligned}
& S=\left\{\mathrm{E} \mid \forall \mathrm{A}\left(\# \mathrm{E}=\#\left(\left(\mathrm{P}_{\text {true }} \cup \mathrm{P}_{\text {false }}\right) \backslash\left(\mathrm{P}_{\text {true }} \cap \mathrm{Q}_{\text {false }}\right)\right)>\# \mathrm{~A}\right)\right\} \\
& \Leftrightarrow S=\left\{\mathrm{E} \mid \forall \mathrm{A}\left(\# \mathrm{E}=\#\left(\left(\mathrm{P}_{\text {true }} \cap \mathrm{Q}_{\text {true }}\right) \cup \mathrm{P}_{\text {false }}\right)>\# \mathrm{~A}\right)\right\} \\
& \Leftrightarrow S=\left\{\mathrm{E} \mid \forall \mathrm{A}\left(\# \mathrm{E}=\#\left(\mathrm{P}_{\text {true }} \cap \mathrm{Q}_{\text {true }}\right)+\# \mathrm{P}_{\text {false }}>\# \mathrm{~A}\right)\right\}^{11}
\end{aligned}
$$

\footnotetext{
${ }^{9}$ Because of the unidiomatic nature of the type of construction of (9) and the complications hinted at in footnote 8 , I refrain from analysing what happens in cases where it is not mutually manifest that $P_{\text {false }} \neq$ $\varnothing$.

${ }^{10}$ The influence of focus on quantification in conditional sentences is well known; see Krifka (1992: 230233 ) and the literature mentioned there.

${ }^{11}$ In terms of the cardinality of sets, (7) is equivalent to (ia) and (10) is equivalent to (ib).

(i) a. $S=\left\{\mathrm{E} \mid \# \mathrm{E}=\#\left(\mathrm{P}_{\text {true }} \cap \mathrm{Q}_{\text {true }}\right)+\# \mathrm{P}_{\text {false }}>0\right\}$

b. $S=\left\{\mathrm{E} \mid \# \mathrm{E}=\#\left(\mathrm{P}_{\text {true }} \cap \mathrm{Q}_{\text {true }}\right)+\# \mathrm{P}_{\text {false }}=0\right\}$
} 
What set this denotes is dependent on the identity of $A$ as well as the number of events in the respective sets. The identity of $A$ has to be pragmatically established. In any scenario, if $A=D=P_{\text {true }} \cup P_{\text {false }}$, then \# $\left(P_{\text {true }} \cap Q_{\text {true }}\right)+\# P_{\text {false }}>\# A$ is false. ${ }^{12}$ Consequently, mostly' $(P \rightarrow Q)$ is always false from a purely truth-conditional perspective under the assumption that $A$ ranges over all (proper or improper) subsets of $D$ that are different from $\left(P_{\text {true }} \cup P_{\text {false }}\right) \backslash\left(P_{\text {true }} \cap Q_{\text {false }}\right)$. Since a communicator is commonly not expected to intend to express a necessarily false proposition, the assumption that $A$ is restricted is mutually manifest. In Kratzer's original horse sale scenario, the most accessible assumption concerning the range of $A$ is that it is restricted to the denotation of If $a$ man buys a horse, he pays for it by cheque. Hence, given that $R_{\text {false }}$ is the set of events for which he pays for it by cheque is false, $A=\left(P_{\text {true }} \cup P_{\text {false }}\right) \backslash\left(P_{\text {true }} \cap R_{\text {false }}\right)$. Thus:

$$
\begin{aligned}
& \#\left(P_{\text {true }} \cap \mathrm{Q}_{\text {true }}\right)+\# P_{\text {false }}>\# A \\
& \Leftrightarrow \#\left(P_{\text {true }} \cap \mathrm{Q}_{\text {true }}\right)+\# P_{\text {false }}>\#\left(\left(\mathrm{P}_{\text {true }} \cup \mathrm{P}_{\text {false }}\right) \backslash\left(\mathrm{P}_{\text {true }} \cap \mathrm{R}_{\text {false }}\right)\right) \\
& \Leftrightarrow \#\left(\mathrm{P}_{\text {true }} \cap \mathrm{Q}_{\text {true }}\right)+\# \mathrm{P}_{\text {false }}>\#\left(\left(\mathrm{P}_{\text {true }} \backslash\left(\mathrm{P}_{\text {true }} \cap \mathrm{R}_{\text {false }}\right)\right) \cup\left(\mathrm{P}_{\text {false }} \backslash\left(\mathrm{P}_{\text {true }} \cap \mathrm{R}_{\text {false }}\right)\right)\right) \\
& \Leftrightarrow \#\left(\mathrm{P}_{\text {true }} \cap \mathrm{Q}_{\text {true }}\right)+\# \mathrm{P}_{\text {false }}>\#\left(\left(\left(\mathrm{P}_{\text {true }} \backslash \mathrm{P}_{\text {true }}\right) \cup\left(\mathrm{P}_{\text {true }} \backslash \mathrm{R}_{\text {false }}\right)\right) \cup \mathrm{P}_{\text {false }}\right) \\
& \Leftrightarrow \#\left(\mathrm{P}_{\text {true }} \cap \mathrm{Q}_{\text {true }}\right)+\# \mathrm{P}_{\text {false }}>\#\left(\left(\mathrm{P}_{\text {true }} \backslash \mathrm{R}_{\text {false }}\right) \cup \mathrm{P}_{\text {false }}\right) \\
& \Leftrightarrow \#\left(\mathrm{P}_{\text {true }} \cap \mathrm{Q}_{\text {true }}\right)+\# \mathrm{P}_{\text {false }}>\#\left(\left(\mathrm{P}_{\text {true }} \cap \mathrm{R}_{\text {true }}\right) \cup \mathrm{P}_{\text {false }}\right) \\
& \Leftrightarrow \#\left(\mathrm{P}_{\text {true }} \cap \mathrm{Q}_{\text {true }}\right)+\# \mathrm{P}_{\text {false }}>\#\left(\mathrm{P}_{\text {true }} \cap \mathrm{R}_{\text {true }}\right)+\# \mathrm{P}_{\text {false }} \\
& \Leftrightarrow 10+998000>1990+998000 \\
& \Leftrightarrow 998010>999990
\end{aligned}
$$

which is false, making mostly' $(P \rightarrow Q)$ false as well, as already argued in section 2 above.

\section{Horse sale arguments do not invalidate the material conditional approach}

In sum, Kratzer $(1986,1991,2012)$ errs in assuming that her horse argument proves that "there are indicative conditionals that cannot be analyzed as material conditionals" (Kratzer 2012: 91). Moreover, given that inferential pragmatic processes as modeled in Gricean and post-Gricean pragmatic theories are always involved in natural language interpretation by humans, it appears that Lewis's (1975) comments on conditional sentences in the scope of sometimes or never do not prove that the denotation of conditional sentences cannot generally be material implication. These claims by Kratzer and Lewis do not provide a solid foundation for strands of argument to the effect that the restrictor approach to the meaning of conditionals is to be preferred over the material implication approach.

From this perspective, the inferences mentioned in the context of the discussion of (7) and (10) above hinge on the mutual manifestness of the fact that $\# P_{\text {false }}>0$ in the given scenario.

${ }^{12}$ In the following exchange, $A=D$ for wise guy $\mathrm{B}$ :

(i) A: Most of the time, if a man buys a horse, he pays cash for it.

B: No, certainly not. Most of the time, in fact all of the time, something just is the case.

On wise guy interpretations see Ariel (2002). 


\section{References}

Ariel, Mira. 2002. Privileged interactional interpretations. Journal of pragmatics 34;8: 1003-1044.

Cantwell, John. 2018. Conditionals. In: Hansson, Sven Ove \& Hendricks, Vincent F. \& Michelsen Kjeldahl, Esther (eds.). Introduction to formal philosophy. Cham: Springer. 131-146.

Edgington, Dorothy. 2001/2014. Indicative conditionals. In: Zalta, Edward N. (ed.). The Stanford encyclopedia of philosophy (Winter 2014 Edition). https://plato.stanford.edu/archives/win2014/entries/conditionals/.

Fintel, Kai von. 2011. Conditionals. In: Heusinger, Klaus von \& Maienborn, Claudia \& Portner, Paul (eds.). Semantics: An international handbook of natural language meaning, vol. 2. Berlin: De Gruyter Mouton. 1515-1538.

Grice, Paul. 1967/1989. Logic and conversation. In: Grice, Paul. Studies in the way of words. Cambridge (MA): Harvard University Press. 22-40.

Hackl, Martin. 2009. On the grammar and processing of proportional quantifiers: most versus more than half. Natural language semantics 17;1: 63-98.

Heim, Irene. 1982. The Semantics of definite and indefinite noun phrases. Ph.D. dissertation. Amherst (MA): University of Massachusetts.

Heim, Irene. 1999. Notes on superlatives. Ms. Massachusetts Institute of Technology. https://semanticsarchive.net/Archive/TI1MTlhZ/Superlative.pdf

Jacobsson, Bengt. 2007. A new look at negative and correlative subject-auxiliary inversion in English. Studia neophilologica 79;1: 35-44.

Kaufmann, Magdalena \& Kaufmann, Stefan. 2015. Conditionals and modality. In: Lappin, Shalom \& Fox, Chris (eds.). The handbook of contemporary semantic theory. 2nd edn. Hoboken (NJ): Wiley-Blackwell. 237-270.

Kotek, Hadas \& Sudo, Yasutada \& Howard, Edwin \& Hack1, Martin. 2011. Three readings of most. In: Ashton, Neil \& Chereches, Anca \& Lutz, David (eds). Proceedings of SALT 21. Ithaca (NY): Cornell University. 353-372.

Kratzer, Angelika. 1986. Conditionals. In: Farley, Anne M. \& Farley, Peter \& McCullough, Karl-Erik (eds.). Papers from the parasession on pragmatics and grammatical theory at the twenty-second regional meeting [of the] Chicago Linguistic Society. Chicago (IL): Chicago Linguistic Society. 1-15.

Kratzer, Angelika. 1991. Conditionals. In: Stechow, Arnim von \& Wunderlich, Dieter (eds.). Semantik: Ein internationales Handbuch der zeitgenössischen Forschung. / Semantics: An international handbook of contemporary research. Berlin: De Gruyter. 651-656.

Kratzer, Angelika. 2012. Conditionals. In: Kratzer, Angelika. Modals and conditionals. Oxford: Oxford University Press. 86-108.

Krifka, Manfred. 1992. A framework for focus-sensitive quantification. In: Barker, Chris \& Dowty, David (eds.). Proceedings of SALT 2. Columbus (OH): Ohio State University. 215-236.

Levinson, Stephen C. 2000. Presumptive meanings: The theory of generalized conversational implicature. Cambridge (MA): MIT Press.

Lewis, David. 1975. Adverbs of quantification. In: Keenan, Edward L. (ed.). Formal semantics of natural language. Cambridge: Cambridge University Press. 3-15.

Liu, Mingya. 2019. Current issues in conditionals. Linguistics vanguard 5;s3: 1-8. DOI: https://doi.org/10.1515/lingvan-2019-0003. 
Partee, Barbara H. 1991. Topic, focus and quantification. In: Moore, Stephen \& Wyner, Adam (eds.). Proceedings of SALT 1. Ithaca (NY): Cornell University. 159-188.

Reed, Lisa A. 1999. Necessary versus probable cause. Journal of philosophical logic 28;3: 289-326.

Sharvit, Yael \& Stateva, Penka. (2002). Superlative expressions, context, and focus. Linguistics and philosophy 25;4: 453-504.

Smith, Neil \& Smith, Amahl. 1988. A relevance-theoretic account of conditionals. In: Hyman, Larry M. \& Li, Charles N. (eds.). Language, speech and mind: Studies in honour of Victoria A. Fromkin. London: Routledge. 322-352.

Sperber, Dan \& Wilson, Deirdre. 1986/1995. Relevance: Communication and cognition. 2nd edn. Oxford: Blackwell.

Contact: breul@uni-wuppertal.de 


\section{Appendix}

\section{Comments on a review by an anonymous reviewer}

In what follows, quotations from the review mentioned in the note at the beginning of this contribution are provided in an indented paragraph introduced by a bullet point followed by my comment on the content of the quotation.

- "Why isn't the relevant comparison class the number of events where the conditional is true versus the number where it's false? [...]

More substantively, for just about any declarative sentence $\mathrm{p}$, the natural reading of 'Most of the time, $p$ ' is one on which it is true iff $p$ is true more often than it is false - at least to my ears."

I disagree. 'Most of the time, $\mathrm{p}$ ' is NOT "true iff $\mathrm{p}$ is true more often than it is false". If it were, 'Most of the time, $p$ ' could hardly ever be truthfully asserted, given that $p$ is contingent and non-generic and not something like 'Something is the case'. (Almost all examples instantiating $\mathrm{p}$ in 'Most of the time, $\mathrm{p}$ ' that you find in corpora are contingent, non-generic and not like 'Something is the case'.) Consider a proposition $\mathrm{p}$ such as 'Roger Federer won at tennis'. For all those innumerable events that are not events of Federer having finished a game of tennis, 'Roger Federer won at tennis' is false. Hence, if the reviewer were right, an utterance of Most of the time, Federer won at tennis would have to be judged as false under any circumstances, contrary to intuition.

- "And why is the 'only contextually relevant alternative conditional' 'If a man buys a horse, he pays for it by cheque'? Why isn't it 'If a man doesn't buy a horse, he doesn't pay for it by cash' or what have you?"

Let us assume that we can construct a context such that 'If a man doesn't buy a horse, he doesn't pay for it by cash' is the contextually relevant alternative conditional to the original example in Kratzer's scenario. For how many events is this conditional true in this scenario under the material conditional analysis? It is true for all 1000000 events, for it is never the case that a man does not buy a horse (antecedent is true) and does pay for it by cash (consequent is false) in this scenario. Hence, the material conditional analysis amounts to the assertion $998010>1000000$, which is false, in concordance with intuition. The challenge for the reviewer is to come up with a conditional that is a plausible relevant alternative to the original example in Kratzer's scenario such that the material analysis results in a contradiction to our intuitive assessment of the original sentence in this scenario. The reviewer has provided none.

- "For example: I can (perhaps) speak truly in saying 'Most of the time Jones wins the lottery' when Jones wins $40 \%$ of all lotteries while everyone else wins only $1 \%$. But this is not at all like what is supposed to be happening with the horse conditionals. Assuming the material analysis, the conditionals are not mutually exclusive, and so shouldn't count as genuine alternatives. After all, given the author's imagined scenario, they're both true in the vast majority of cases."

The reviewer's example (Most of the time Jones wins the lottery) is evaluated by determining the number of events for which 'Jones wins the lottery' is true (40\%) and comparing that with the number of events for which 'X wins the lottery', 'Y wins the lottery' etc. ( $1 \%$ for each) are true, where X, Y etc. are persons other than Jones and where these propositions are relevant alternatives. This is analogous to how I treat the horse 
conditional in Kratzer's scenario. I determine the number of events for which If a man buys a horse, he pays cash for it is true (998010 times) and compare that with the number of events for which If a man buys a horse, he pays for it by cheque is true (999990 times). Since 998010 is less than 999990 If a man buys a horse, he pays cash for it comes out as false under the material conditional analysis, as claimed in the paper. In real life, the number of all events cannot be known, of course. But it need not be known, we can assume it to be some number, let us say $e$. If we assume $e$ instead of 1000000 , the material analysis tells us that the number of events for which If a man buys a horse, he pays cash for it is true in Kratzer's scenario is $e-1990$ while the number of events for which If a man buys a horse, he pays for it by cheque is true is $e-10$.

- "I should also mention that it's not clear to me how the view is supposed to handle adverbs of quantification like 'Nearly all of the time' or 'Almost without exception' or even 'More often than not'. To my knowledge none of these exhibits the kind of alternative-sensitivity that plays a role in the author's impressionistic treatment of the 'most of the time' case, yet each generate all the same problems for materialism."

Just as 'Most of the time, $\mathrm{p}$ ' is NOT "true iff $\mathrm{p}$ is true more often than it is false", so 'Nearly all of the time, $p$ ' (or 'Nearly always, p') or 'Almost without exception, p' is NOT true iff $p$ is true for a number of events that comes close to the total number of events. This is obvious. The intuitively most salient interpretation of 'Nearly all of the time, she drank her tea with milk' does not yield the evaluation 'false' on the basis of the reasoning that however often she drank her milk with tea, this is tiny fraction - and by no means close to - the number of events that are not events of her drinking her tea with milk. Again, the evaluation of propositions $\mathrm{p}$ - conditionals or otherwise - in the scope of these adverbials is done by comparing the number of events for which $p$ is true with the number of events for which relevant alternative propositions (such as 'she drank her tea without milk') are true. These cases do not raise any problems that pertain to the material implication analysis of conditionals.

- '"Monkey's uncle' conditionals like 'If Jones is at work then I'm a monkey's uncle' have the effect of inviting the interlocutors to tollens the antecedent (based on their common knowledge of the falsity of the consequent). But I find it very difficult to get any such effect with conditionals embedded under adverbial quantifiers: 'Sometimes, if Jones is at work then I'm a monkey's uncle' seems outright infelicitous to me-like a botched attempt at sarcasm or something."

I suspect that the reason for the infelicity of the reviewer's example is an incompatibility of the predicate a monkey's uncle, which is an individual level predicate, with the quantifier. To give another example in addition to the one in the paper, whose context involves a recently engaged janitor who has quickly acquired a reputation for always being unfriendly:

(1) A: What do you think of our new janitor?

B: Well, sometimes, if he is sober, he's friendly.

I leave it to the larger readership to decide whether my example from the paper and the preceding one are infelicitous. I leave it to the larger readership to decide whether the examples are incapable of conveying 'never, $A$ ', where $A$ is the antecedent of the respective conditional. 
- "Setting aside the difficulties in reconstructing a clear pragmatic explanation of why we ignore cases in which no one buys a horse in assessing sentences like 'Sometimes if a man buys a horse he pays cash for it', there are basic empirical problems that face any such view. For one, pragmatic inferences tend to be cancelable. We'd thus expect that I should be able to say things like 'Sometimes if a man buys a horse he pays cash for it; I say that because sometimes a man doesn't buy a horse'. But that's terrible."

It is not clear to me what exactly the proposition is that is supposed to be canceled in the reviewer's example. Anyway, it is well-known that not all types of pragmatic inference are cancelable. The type that has been called conventional implicature is not; the type of what Wilson \& Sperber call an implicated premise, as in their (1981) example (2), does not seem to be either.

(2) A: Do you ever talk to Charles?

B: I never talk to plagiarists.

In order to be able to make sense of B's utterance, it is necessary to infer the proposition 'Charles is a plagiarist' and to assume that it is an assumption held by B. It would be hard to come up with an interpretation of B's utterance, if they canceled, or rather preempted the inference by adding something like 'But I do not intend to insinuate that Charles is a plagiarist'. Even more importantly, note that the wise-guy interpretation mentioned in footnote 12 of the paper works also in a scenario where 1990 out of 2000 horse buying events are settled by cash. That is, the wise guy does in fact cancel the inference that the domain of events be restricted to horse buying events. This is only possible if semantically the domain is not restricted to those events.

- "Likewise, pragmatic effects explain why it is bad to assert certain kinds of sentences. But they tend to be silent on whether it is okay to believe (or assign high credence to) the propositions expressed by those sentences. And it seems just as bad to believe that sometimes if a man buys a horse he pays cash for it as it does to assert it (when one knows that sometimes a man buys a horse but never does a man pay cash for it)."

Let us assume $P$ to be the proposition 'a man buys a horse' and $Q$ the proposition 'he pays cash for it', with he referring to the man who buys a horse and it referring to the horse that the man buys. Then, as I say in the paper, 'sometimes if a man buys a horse he pays cash for it', i.e. sometimes' $(P \rightarrow Q)$, denotes the set $S$ of sets of events $E$ for which holds:

(3) $\mathrm{S}=\left\{\mathrm{E} \mid \mathrm{E}=\mathrm{P}_{\text {true }} \cap \mathrm{Q}_{\text {true }} \neq \varnothing \vee \mathrm{E}=\mathrm{P}_{\text {false }} \neq \varnothing\right\}$

where $P_{\text {true }}$ is the set of events for which $P$ is true, $Q_{\text {true }}$ is the set of events for which $Q$ is true and $P_{\text {false }}$ the set of events for which $\mathrm{P}$ is false. Now, let us also assume, as the reviewer suggests, that I know "that sometimes a man buys a horse but never does a man pay cash for it". Do I believe sometimes' $(P \rightarrow Q)$ ? If I were to believe that, I would have to believe that the events that constitute the world in which sometimes a man buys a horse but never does a man pay cash for it, constitute a set $W$ that is a member of $S$. However, the set $W$ is certainly not a member of $\left\{E \mid E=P\right.$ true $\left.\cap Q_{\text {true }} \neq \varnothing\right\} ; W$ is certainly not a member of the set of non-empty sets of events for which $P$ and $Q$ are both true. But nor is $W$ a member of $\left\{E \mid E=P_{\text {false }} \neq \varnothing\right\} ; W$ is not a member of the set of non-empty sets of events for which $P$ is false, for $W$ is a set of events for some of which $P$ is false and some others of which $P$ is true. Hence, the material analysis predicts that I 
do not believe 'sometimes if a man buys a horse he pays cash for it' given that I know that sometimes a man buys a horse but never does a man pay cash for it, contrary to what the reviewer assumes.

- "One immediate point to make, which the author briefly acknowledges (pp. 5-6), is that this is essentially the same story as is given by the proponent of the restrictor analysis of the conditional, except in pragmatic rather than semantic form. This needn't be a strike against the view in its own right [...]."

Here the reviewer tries to turn the table, implicating (while generously hedging the implicature) that my pragmatic derivation of Lewis's and Kratzer's semantic conclusions on the basis of a semantic material implication approach to conditionals does not really offer anything new, interesting or important. Well, if this is supposed to be a veiled call for letting linguistics and analytical philosophy go and for doing something more important such as fighting the destruction by humankind of its ecological environment, I am prepared to grant the reviewer a point. If, however, the reviewer intends no such suggestion, but intends her or his remark to apply to linguistics and analytical philosophy, I grant her or him nothing more than the execution of a trite piece of rhetoric here, aiming to delude those ignorant of the fact that the discussion of the question of what phenomena are best accounted for in terms of semantics or in terms of pragmatics (if not by making use of these terms) has been a very prominent one in the history of philosophy and linguistics.

\section{Reference}

Wilson, Deirdre \& Sperber, Dan. 1981. On Grice's theory of conversation. In: Werth, Paul (ed.). 1981. Conversation and discourse: structure and interpretation. London: Croom Helm. 155-178. 